\title{
EL ESTADO COMO SUJETO INMORAL
}

[The State as an Immoral Subject]

\author{
Miguel Ayuso* \\ Universidad Pontificia Comillas, Madrid, España
}

\section{RESUMEN}

A partir de una reconstrucción matizada de las relaciones entre ética y política en el pensamiento clásico, se aborda la evolución del Estado moderno desde el ángulo de la moral. De artefacto pretendidamente neutro al inicio aquél ha llegado a convertirse en instrumento "moralizador" de una "ética sin moral", tras haber pasado por la fase fuerte del "Estado ético" hegeliano y la débil del Estado servidor de la sociedad civil posmoderna.

\section{Palabras clave}

Estado moderno - Estado ético Sociedad civil posmoderna - Estado moralizador.

\section{ABSTRACT}

From a nuanced reconstruction of the relationships between ethics and politics in the classical thought, we address the evolution of the Modern State from the moral standpoint. What started as an allegedly neutral artifact has become a "moralizing" tool of an "ethics without moral", through the strong phase of the Hegelian "Ethical State" to the weak phase of the Servant State of post-modern civil society.

KeYWORDS

Modern State - Ethical State Post-Modern Civil Society - Moralizing State.

Recibido el 11 de noviembre de 2015 y aceptado el 7 de diciembre de 2015

* Doctor en Derecho por la Universidad Pontificia Comillas de Madrid (España); doctor honoris causa por la Universidad de Udine (Italia); profesor ordinario en la Facultad de Derecho de la Universidad Pontificia Comillas de Madrid. Dirección postal: Facultad de Derecho de la Universidad Pontificia Comillas de Madrid Alberto Aguilera 23, 28015 Madrid, España. Correo electrónico: mayuso@icade. comillas.edu 


\section{INTRODUCCIÓN}

Si hacemos caso, como conviene, a la sabiduría clásica, comencemos con el examen del título que se nos ha encomendado abordar: "initium doctrinae sit consideratio nominis".

"El Estado como sujeto inmoral" nos introduce, de un lado, en el cuadro de la relación entre política y ética, mientras que, de otro, nos lleva particularmente al campo del Estado como encarnación de la política moderna y sus metamorfosis. En el seno de éstas, finalmente, es oportuno incluir una referencia a la realidad perenne del Gobierno.

\section{II. ÉTICA Y POLÍTICA}

El tema es bien conocido, pero aun así es oportuno decir algo al respecto. En dos órdenes: el más concreto de la articulación de la política con la ética y el más amplio de la distinción de la moral con la ética.

\section{La articulación de la politica con la ética}

El primero reclama, a su vez, dos aproximaciones sólo en apariencia opuestas, pues en el fondo resultan convergentes: la de la naturaleza moral de la política y la de la naturaleza política de la moral.

a) Para el pensamiento clásico, en una primera consideración, la política es una ciencia ética. Aristóteles, como sabemos, habla en su Ética a Nicómaco de una "filosofía de las cosas humanas"1. Frente a las ciencias teoréticas, cuyo objeto tiene en sí mismo el principio del movimiento, las ciencias prácticas versan sobre objetos practicables, que tienen el principio del movimiento en la acción humana. De ahí las características de que son en cierto sentido inexactas (pues "todo lo que se dice de las acciones debe señalarse en esquema y no con rigurosa precisión” ${ }^{2}$, que su finalidad "no es el conocimiento sino la acción" ${ }^{3}$, que tienen un carácter ético, que están en contacto estrecho con la experiencia ("debemos, pues, acaso empezar por las [cosas] más fáciles de conocer para nosotros" ${ }^{4}$ ) y que tienen un método propio plural 5 .

${ }^{1}$ Arist., Ética a Nicómaco, X, 9, 1181b 15-16.

${ }^{2}$ Ibíd., II, 2, 1104a 1-4.

${ }^{3}$ Ibíd., I, 2, 1095 a 6.

${ }^{4}$ Ibíd., I, 4, 1095b 2-4.

${ }^{5}$ Cfr. CRESPO, Ricardo, La ciencia práctica y sus características: ensayo de sistematización y aplicación a la economía, en Analogía Filosófica. Revista de Filosofía, Investigación y Difusión, 11 (Ciudad de Méjico, 1997), 2, pp. 87-112. 
Que tienen carácter ético - detengámonos un poco más en el asunto en razón del tema que estamos desarrollando- débese a que toda acción humana es intrínsecamente moral ${ }^{6}$. Ahora bien, eso no quiere decir que sean la ética. Puesto que son ciencias que versan acerca de tipos de acciones humanas de cierta complejidad, lo que obliga considerar analógicamente la intervención de la razón en su juicio. Es aquí donde suele introducirse el discurso de la ciencia denominada social con todas las dificultades que comporta. Tanto para quienes separan ciencias morales y sociales de modo tajante, como para quienes postulan la subalternación de éstas a aquéllas ${ }^{7}$. Parte del problema deriva de la distinción comptiana entre ciencias positivas (descriptivas) y normativas (prescriptivas), basada en la escisión entre el ser y el deber ser. Que presenta, para empezar, y sin entrar en grandes honduras, la debilidad de hacer depender el objeto de la ciencia de la finalidad perseguida por el científico. No hay duda, así, de que corresponde al moralista indagar las finalidades objetivas inscritas en la vida social, como al teólogo por cierto le corresponde hacerlo a la luz de la gracia. Lo que en cambio resulta dudoso es que cuando el sociólogo o el economista examinan los hechos (humanos) sociales (no, claro está, para prescribir, sino para describir y explicar) deban excluir del campo de su consideración "lo que debe ser" so pretexto de limitar su observación a lo que es: porque "lo que debe ser" no es una categoría arbitraria proyectada arbitrariamente por quien se adhiere a una moral. La moral existe y brota de las finalidades objetivas inscritas en la naturaleza (total) del hombre, física y moral: el matrimonio está, en realidad, ordenado a la paternidad

${ }^{6}$ Crespo, Ricardo, El acto humano: Aristóteles y Tomás de Aquino, en Sapientia, 51 (Buenos Aires) 199 (1996), pp. 7 ss..

${ }^{7}$ Álvaro D'ORs, por ejemplo, en un intento muy agudo de clasificación de las ciencias, "recupera" para las morales al derecho y la política, pero -merced a la introducción del tropismo colectivo como objeto de las sociales- se ve obligado a arrojar fuera de aquéllas a la economía. Pueden verse las objeciones que he formulado en Ayuso, Miguel, La filosofía jurídica y política de Alvaro d Ors, en Altuve, Fernán (editor), Homenaje a Álvaro d' Ors (Lima, Dupla, 2001), especialmente pp. 132-133. Marcel Clément, por ejemplo, entiende que las ciencias morales se centran en los actos humanos voluntarios, esto es, en el orden que la razón introduce en las operaciones de la voluntad; mientras que las sociales estudian las acciones humanas en la vida social. Ahora bien, distingue en los hechos sociales aspectos necesarios, que derivan de la naturaleza de las cosas, y aspectos contingentes, que dependen del libre arbitrio de los hombres o del carácter fortuito de los acontecimientos: la ciencia que estudia los primeros es la filosofía social y su objeto propio es lo que reclama la ley natural en la vida social, mientras que la sociología positiva se ocupa de los segundos. Véase Clément, Marcel, Catéchisme de sciences sociales (Paris, Nouvelles Éditions Latines, 1959), pp. 10-14. 
y a la maternidad; la economía se ordena, en realidad, a las condiciones materiales de la vida humana completa ${ }^{8}$.

De lo que se trata, por tanto, es de que el estudio verdaderamente científico de la vida social en su última concreción debe presuponer las nociones y las verdades generales de lo que llamamos la filosofía moral: la ética, la economía (en sentido clásico) y la política, que son formalmente prácticas. De modo que las ciencias sociales propiamente dichas constituyen como una continuación de la última hacia una concreción siempre mayor. Si las llamamos experimentales no es por oposición a las ciencias morales, que también dependen de la experiencia, sino porque surgen de una experiencia mucho más circunstanciada. De todos modos, el estudio de la vida social, sea general o experimental en el sentido que acabamos de indicar, tiene su principio en el bien común?.

b) En una visión clásica de la ética aparecen tres caracteres mayores: practicidad, politicidad y normatividad. En lo que hace al segundo, que es el que aquí nos interesa, y como ya se ha visto en lo anterior, la separación entre ética y política es moderna y quizá pueda encontrarse por vez primera, si bien todavía no totalmente articulada, en Maquiavelo. Aunque haya que esperar al liberalismo para hallarla plenamente afirmada. En cambio, Aristóteles identifica, cuando existe un buen gobierno, hombre bueno y buen ciudadano: el bien de la persona es el mismo que el bien de la ciudad, del que difiere sólo en el grado de perfección. El saber ético es el que se refiere al fin de toda la vida humana, por lo que le corresponde dirigir todas las demás actividades. Así pues, en cuanto arquitectónico, o sea referido a los principios últimos de toda la vida humana, es también político. La vida verdaderamente política -afirma Aristóteles- no se constituye en vista de alianzas comerciales ni para alcanzar mayor seguridad, sino para que los ciudadanos se ocupen de lo que son los otros, de su éthos

${ }^{8}$ Clément, Marcel, Charles de Koninck et les sciences sociales, en Itinéraires, 66 (Paris, 1962), pp. 104 ss.

${ }^{9}$ DE KonIncK, Charles, Sciences morales et sciences sociales, en Laval Philosophique et Théologique, 1 (Québec, 1945) 2, p. 196. No se trata, por tanto, de liberar las llamadas ciencias sociales de la gravitación de la ciencia moral, esto es, de decir que no son morales, sino de considerar en su complejidad el conjunto de hechos a las que aquéllas sujetan. Porque bajo el término de ciencias sociales se comprenden también ciencias experimentales no morales que se relacionan con el objeto de ciencias sociales estrictamente morales. Estas últimas, en efecto, no se forman en el vacío, sino que dependen de ciertas ciencias experimentales puramente naturales. Y la dependencia es tan estrecha que el campo al que se debe aplicar el estudioso es tan vasto que no puede expresarse sino con un término equívoco. El término ciencias morales no lo permite, mientras que el de ciencias sociales es suficientemente ambiguo (Ibid., p. 197). 
o virtud: "La actividad realmente humana es aquella por la que se tiende al bien no sólo propio, sino fundamentalmente de otros. El hombre se perfecciona a sí mismo en su actividad, en la medida en que ésta se ordena a un bien que lo excede. En definitiva, en tanto se ordena a un bien común que no es otra cosa que el mismo bien humano, pero en cuanto se alcanza en comunidad. Esta es la razón más de fondo del carácter social $\mathrm{y}$, en último término, político del hombre: siendo buen amigo se hace a sí mismo bueno" 10 .

\section{2. Ética y moral.}

Si los términos "ética" y "moral" se han entendido de modo general como sinónimos, respectivamente procedentes del griego y de latín, también es dado hallar versiones que los distinguen y aun los contraponen. Estas interpretaciones han tendido a subrayar los aspectos colectivos de la ética frente a los individuales de la moral. A la vista de lo que aquí nos interesa, voy a resumir a continuación lo que he tratado en ocasión anterior ${ }^{11}$.

Así, por ejemplo, desde un ángulo marcadamente jurídico, se ha podido decir: "La Ética es el orden de conducta recta socialmente vigente. Se diferencia de la Moral en que ésta se refiere a los hombres individualmente considerados: el imperativo ético es social, en tanto el moral es individual. Ambos imponen deberes a la conciencia de las personas, pero puede haber alguna divergencia entre la Ética y la Moral cuando el régimen de la conciencia personal discrepa de la moralidad socialmente aceptada, como ocurre en los casos de objeción de conciencia [...]. Pero la diferencia esencial está en que la Ética, en la medida en que es fundamento del orden jurídico, da lugar a la exigibilidad coactiva de unos determinados deberes, al control judicial de su conveniencia, en tanto los preceptos morales no trascienden de la conciencia, que es individual"12.

También ha podido abordarse la cuestión en un plano eminentemente cultural: "El ethos es la manera en que un grupo entiende y se acopla a las reglas de la ley moral universal, que precisamente por su universalidad suele llamarse ley natural [...]. La moral es la ley natural por la que todos

${ }^{10}$ WIDOw, José Luis, Introducción a la ética (Santiago de Chile, 2009), principalmente el capítulo $1^{\circ}$ Puede verse también del mismo autor la monografía $L a$ naturaleza politica de la moral (Santiago de Chile, 2004).

${ }^{11}$ Véase Ayuso, Miguel, Sobre la ética pública. Una visión problemática, en Verbo, 491-492 (Madrid, 2011), pp. 49 ss.

${ }^{12}$ D'Ors, Álvaro, Nueva introducción al estudio del derecho (Madrid, Civitas, $1999)$, $\$ 52$, pp. 71-72. De gran interés, como siempre, no deja de levantar algunas dificultades que aquí no se pueden tratar. 
y cada uno de los seres humanos son inexorablemente morales, es decir, responsables y libres, sin que sea posible otra explicación [...]. Según lo anterior, la Moral es única y la Ética plural. La causa es que, debido a condiciones y circunstancias físicas e históricas, existen grupos humanos diferenciados, cada uno con su ethos particular según la interpretación de la ley moral natural por la religión respectiva. Esto puede dar lugar a una serie de inversiones o tergiversaciones intelectuales: por una parte, la ley moral natural es universal y, en rigor, todo debiera ajustarse a ella; por ejemplo, según la conocida máxima "fiat iustitia pereat mundus". Sin embargo, por otra, en el mundo real, las leyes éticas -los usos, las costumbres, las tradiciones- son plurales, es decir, distintas en grado mayor o menor. La aporía consiste en que la Moral se refiere a cómo se debe actuar, ya que la persona es libre; en contraste, el éthos, se refiere a cómo hay que actuar, puesto que la convivencia en un grupo exige ajustarse a sus pautas [...]. Esto crea obviamente un problema: por un lado, la conducta individual, a la que se refiere la Moral, ha de ser la apropiada al éthos del grupo al que pertenece una persona, pues regula cómo tiene que ser la conducta colectiva; por otra, es posible que la conducta particular de una persona no se ajuste, se desvíe, contradiga al éthos o se oponga a él"13.

Se hace preciso, pues, indagar sobre la raíz idealista de esa distinción entre ética y moral. El pensamiento del iusnaturalismo racionalista de la modernidad buscaba conciliar la libertad (verdadero reino moral) con la coacción (verdadero reino de la práctica), en lo que originaba una verdadera paradoja, que Rousseau llamaba "verdadera cuadratura del círculo" ${ }^{14}$, y que consistía en hacer que el poder fuese libertad, eliminando una de las partes del problema político ${ }^{15}$. Idea a la que Hegel daría forma con su "sistema", pues solamente en el nivel del Estado, en la que se ha traducido por "eticidad", el derecho adquiría su verdadera naturaleza como culminación del proceso de realización de la libertad. Con lo que la verdad del derecho se conseguía por su confusión con el Estado ${ }^{16}$.

Es claro que en un tal planteamiento reside un doble error. En lo que toca a la ética, en primer lugar, se convierte en pura costumbre; mientras

${ }^{13}$ Negro, Dalmacio, El “éthos": religión y politica, en Razón española, 162 (Madrid, 2010), pp. 33-36.

${ }^{14}$ Rousseau, Jean-Jacques, Considérations sur le gouvernement en Pologne, lib. I. Se escribieron entre 1771 y 1772 y se publicaron por primera vez en la edición de sus obras completas de 1782 .

${ }^{15}$ Castellano, Danilo, L'ordine della política (Napoli, Edizioni Scientifiche Italiani, 1997), p. 38.

${ }^{16}$ Almoguera, Joaquín, El ordenamiento del derecho: orden ético, orden politico y orden estatal, en Verbo, 487-488 (Madrid, 2010), pp. 601 ss. 
que en lo que hace a la moral, a continuación, no puede sino resolverse en sola subjetividad. No se trata, respecto a lo primero, de negar el valor humano de la consuetudo, sino sólo de poner de relieve que la praxis humana no puede no ser racional, en el sentido clásico de penetración por la inteligencia de la realidad ascendiendo del hecho al principio, por lo que se deshumaniza cuando se contenta con la repetición que no hace problemático el principio ${ }^{17}$. Al igual que, en cuanto a lo segundo, no se niega la función mediadora de la conciencia moral entre la ley y la acción, aunque sí se rechace el subjetivismo nihilista en que concluye una moral así concebida separada de la ética.

El profesor Danilo Castellano lo ha expresado con particular sutileza, sin dejar de prestar atención a la posteridad del planteamiento en nuestros días: "Tras el idealismo que distinguió y a veces contrapuso ética y moral, aunque en continuidad con el mismo, se sostiene actualmente que es posible (según algunos, necesaria) una ética sin moral y que la ética sería el producto de una convención teórica o simplemente práctica, en ocasiones exclusivamente de hecho. La ética sería necesaria para la convivencia y, por lo mismo, exigida por ésta. Existiría, por tanto, un orden ético pero no $e l$ orden ético. El orden, pues, sería meramente convencional y funcional. Tendría una existencia nominalista y no óntica. No podría prescindirse de él, pero dependería de la representación del orden creado por los individuos o la colectividad. La representación, por ello, sería constitutiva del orden ético y no una representación (propia o impropia, poco importa ahora) del orden ético en sí y por sí mismo. Esto vale en el nivel del orden ético considerado bajo la perspectiva moral, política o jurídica. Está ahí implicada toda la filosofía de la praxis, que no sería, por ello, filosofía como contemplación de la acción (esto es, como acogida de la naturaleza de la acción), sino acción "libre" de la "filosofía". La "filosofía", entendida de esta manera, orientaría, sí, la acción, pero esta sería ya libre y liberada de todo vínculo, con exclusión del dictado por el fin operativo asumido. La opción que, en cuanto tal, no depende de otra cosa que de la libre autodeterminación de individuos o pueblos, constituiría -en último término- el fundamento de la filosofía. Por eso, ésta sería la epifanía de la libertad absoluta, si bien en su curso encuentra -como se acaba de decirvínculos y reglas impuestas por el fin que la opción ha decidido perseguir"18.

${ }^{17}$ Castellano, Danilo, La razionalità della política (Napoli, Edizioni Scientifiche Italiani, 1993), pp. 9 ss.

${ }^{18}$ Castellano, Danilo, Orden ético y derecho (Madrid, Marcial Pons, 2010), pp. $17-18$. 


\section{Estado y moral.}

Tras los prenotandos anteriores hemos de acercarnos ya a la relación -que en título despunta de modo decidido y polémico- del Estado con la moral. Podemos desarrollar la consideración en tres estratos: el del nacimiento del Estado como artefacto (pretendidamente) neutro moralmente; el de su conversión en un Estado productor de la ética (Spinoza), hasta el punto de hablarse de "Estado ético" (Rousseau, Hegel); y el de su evolución hacia un Estado al servicio de la voluntad individual de los ciudadanos que concluye en un Estado "moralizador", aunque inmoral.

\section{El EsTADO ARTEFACTO}

El Estado debe ser situado entre las formas de organización de la comunidad política; debe ser, por tanto, situado en la historia. Como, en primer término, no es la comunidad política, connatural al hombre, sino una simple forma histórica de su concreción, y en buena medida -por lo que ha de seguir se verá- de su desnaturalización, y como, en segundo lugar, no es el gobierno personal sino una construcción artificial, las expresiones Estado romano o Estado medieval, popularizadas por los historiadores alemanes de finales del siglo XIX y comienzos del XX, como Mommsen o Gierke, no son otra cosa que anacronismos: "El Estado no ha existido siempre, ni tampoco podemos decir que no dejará de existir algún día [...]. Es cierto que una sociedad asentada como unidad relativamente independiente en un determinado territorio se constituye siempre con un sistema de gobierno común supra-familiar. Para designar esta forma de existencia social que siempre ha existido y difícilmente puede desaparecer podemos servirnos de la palabra república, con tal que la despojemos de su referencia a una concreta forma de gobierno -en contraposición a "reino"-, y no pretenda significar más que lo que literalmente quiere decir: "cosa pública", o mejor, "gestión pública". El Estado propiamente dicho aparece en el siglo XVI como reacción superadora de la anarquía provocada en algunos pueblos europeos por las guerras de religión. España, al verse afortunadamente libre de estas guerras, no sintió verdaderamente la necesidad del Estado, y por eso la teoría del Estado -propia de los "políticos", como se decía entonces- fue mal recibida por nuestros pensadores clásicos, y, de hecho, el Estado sólo se ha ido realizando en España con gran lentitud y dificultad, y siempre impulsado por influencias extranjeras, sobre todo francesas, pues es en Francia donde la idea de Estado alcanzó su máxima nacionalización, empezando por la obra de Bodin, primer gran teórico del Estado"19.

${ }^{19}$ D'Ors, Álvaro, Una introducción al estudio del derecho (8a edición, Madrid, Rialp, 1989), pp. 118-119. 
No se puede separar el nacimiento del Estado - del Estado moderno- de un complejo de factores ideológicos que, al tiempo que militaban para dar muerte a la vieja Cristiandad, hacían posible el surgimiento de la nueva forma política que había de sustituirla. El tradicionalismo español, en el horizonte de la conocida oposición por él trazada entre Cristiandad y Europa, ha hablado de "cinco fracturas sucesivas" entre 1517 y 1648, "cinco horas de parto y crianza de Europa, cinco puñales en la carne histórica de la Cristiandad": la ruptura religiosa del luteranismo, la ruptura ética del maquivelismo, la ruptura política del bodinismo, la ruptura jurídica del hobbesianismo y la ruptura social de la paz de Westfalia ${ }^{20}$.

Lutero desgarró la unidad entre el mundo natural y el sobrenatural, pues el reino espiritual tiene por finalidad la salvación por la fe y el reino temporal la vida natural del hombre, sin que haya relación entre uno y otro $^{21}$. Maquiavelo trastrocó el planteamiento del problema básico de la política tradicional, que partía de la cuestión de derecho, es decir, de la búsqueda de la justicia general, sustituyéndolo por el intento de esclarecer la cuestión de hecho, esto es, atendiendo a cómo son los hombres y cómo pueden ser manejados ${ }^{22}$. Al colocar la causa eficiente en lugar de la finalidad moral rebajó de un modo "realista" la finalidad de la política a ser una técnica puesta al servicio del poder ${ }^{23}$. Bodino, por su parte, al dotar del rasgo de la soberanía al poder político, hizo que éste absorbiera, de un lado, el derecho, y de otro los poderes sociales ${ }^{24}$. Por eso ha podido

${ }^{20}$ ElíAS DE TEJADA, Francisco, La monarquía tradicional (Madrid, Rialp, 1954), pp. 37.

${ }^{21}$ Escribe Lutero, Weimarer Ausgabe, XXXII, 440,9: "Ein Furst kan wol ein Christen sein, aber als ein Christ mus er nicht regieren: und nach dem er regiret, heisst er nicht ein Christ sondern ein Furst. Die person ist wol ein Christ, aber das ampt odder Furstenthumb gehet sein Christentum nicht an" ("Un príncipe puede ser sin duda cristiano, pero no tiene por qué gobernar como cristiano. Como gobernante no se le llama cristiano sino príncipe. La persona es cristiana sin duda, pero el principado no tiene nada que ver con su cristianismo").

${ }^{22}$ STRAuSs, Leo, Natural Right and History (Chicago, Chicago University Press, 1950), pp. 178-179.

${ }^{23}$ DE CORTE, Marcel, L'homme contre lui-même (Paris, Nouvelles Éditions Latines, 1962), pp. 190 ss. Escribe VALLET DE GoYTISOlO, Juan, La nueva concepción de la vida social de los pactistas del siglo XVII: Hobbes y Locke, en Verbo, 119-120 (Madrid, 1973), p. 909: "La eficacia, para conseguir el bien de la patria, constituía así el más alto bien, y desplazaba todas las preocupaciones por la justicia. Sin duda se le escapó que esta regla ha de producir la corrupción de gobernantes y gobernados, la cual, a plazo más o menos largo, puede llegar a descomponer el país, empezando por sus elementos más singulares".

${ }^{24}$ Véase, respecto de lo primero, a saber, el derecho, Negro, Dalmacio, La metodología jurídica de Vallet de Goytisolo ante la política, en Verbo, 427-428 (Madrid, 
observarse que con la doctrina de la soberanía se establece la identidad entre lo legal y lo legítimo, afirmando -coherente pero absurdamente- que el criterio del bien y del mal, de lo justo y de lo injusto, se constituye a través del ordenamiento jurídico positivo, cuyo fundamento no es otro que el poder, pero ni siquiera el poder político (que debiera estar cualificado), sino el poder desnudo ${ }^{25}$. Hobbes quiso restaurar los principios "morales" de la política, pero sólo al nivel del "realismo" de Maquiavelo, es decir, prescindiendo de las virtudes morales, que de acuerdo con la tradición clásico-cristiana buscaban la perfección del hombre como animal racional y social ${ }^{26}$. Esto es, "si Maquiavelo separó la moral y el derecho natural de la política, Hobbes, para volverlos a enlazar con ésta, los rebajó despojándolos de toda preocupación por la perfección humana. Para eso tuvo necesidad de cambiar no sólo el concepto sino también el fundamento de la ley natural [...]". En efecto, el concepto de la naturaleza sufrió un radical cambio de significado en la perspectiva de los pactistas. El hombre "deja de ser contemplado como un animal racional y político, y en todas sus relaciones con el orden de la creación. Se le reduce a individuo aislado y abstracto y, además, la observación se circunscribe a contemplar una sola de sus apetencias o cualidades, que se estima como la fundamental [...]”. Por otra parte, estos autores "ya no buscaron el fundamento de la ley natural en la naturaleza, ni en el fin del hombre, sino aislándolo en sus orígenes, en su estado de naturaleza", del que extrajeron un dato determinante (el temor a la muerte violenta en Hobbes, el deseo innato de bienestar en Locke o la libertad natural en Rousseau ${ }^{27}$.

2004), p. 590. Afirma que Bodino preparó la sustracción de la titularidad del derecho por el pueblo, que consumó un siglo después Thomas Hobbes, con las abstracciones del "Estado" y la "sociedad", sobre las que extendió el "contrato". Es claro que esa referencia a derecho y pueblo debe entenderse en el sentido tradicional del derecho predominantemente consuetudinario y no convertido aún a la categoría de la "legislación". Cfr. Ayuso, Miguel, De la ley a la ley. Cinco lecciones sobre legalidady legitimidad (Madrid, Marcial Pons, 2001), cap. $2^{\circ}$. En cuanto a lo segundo, esto es, los poderes sociales, VALleT De GoYTisolo, Juan, Poderes políticos y poderes sociales. Totalitarismo y distribución de poderes, en Verbo, 285-286 (Madrid, 1990), pp. 761 ss.

${ }^{25}$ Bodino, Los seis libros de la República, lib. I, cap. $8^{\circ}$. Aunque no niega ni el orden divino ni el natural, al calificar el poder del príncipe de "no limitado, ni en poder, ni en responsabilidad, ni en tiempo", pone las bases de lo que sólo tras revestirse del ropaje de la revolución dejará ver su faz disolvente. El profesor CASTELLANO, Danilo ha penetrado profundamente el significado de la soberanía, como se ve en La naturaleza de la política (Barcelona, Scire, 2006), pp. 26 ss. También resultan interesantes las observaciones del profesor Gentile, Francesco, Intelligenza politica e ragion di Stato (2a ed.ición Milano, Giuffrè, 1984).

${ }^{26}$ STRAuss, Leo, cit (n. 22), pp. 182 ss.

${ }^{27}$ Vallet de Goytisolo, Juan, La nueva concepción, cit. (n. 23) , pp. 909-912. 
Así pues, en el Estado aparece la voluntad humana, que no puede ser injusta, liberada de la naturaleza, de la moral, del derecho y los poderes sociales, de cualquier sustancia comunitaria...

\section{El Estado ÉTICO}

La conversión del Estado (éticamente) neutro en Estado productor de la ética se comprende fácilmente. Es el Estado (stricto sensu) moderno, pues más latamente todo Estado es moderno bajo un cierto ángulo, esto es, el teorizado por Rousseau y recogido por Hegel ${ }^{28}$. Ambos entienden que la ética es un producto del Estado y que, por tanto, la ley positiva es la fuente de la moral y de la justicia. La legalidad constituye, pues, el criterio supremo y lo que el Estado establece es "moral” y "justo" sólo porque ha sido establecido por el Estado. Una tal doctrina representa la aniquilación de la ética y la reducción del derecho en última instancia a expresión de un mero poder que pretende legitimarse a sí mismo. Lo que sirve para los regímenes llamados totalitarios, pero también para los regidos por la democracia ("moderna"), tanto la definida como "representativa" como la "deliberativa" propuesta y defendida por (entre otros) Habermas ${ }^{29}$.

Spinoza había explicado con toda claridad las raíces de ese "Estado ético". Escribe que "siempre que en un Estado se admita el ejercicio de una autoridad independientemente del poder político habrá, necesariamente, escisión y lucha, como ocurrió a los reyes de Israel, a los que pretendían juzgar los Profetas". A partir de aquí es claro que "sólo el poder político puede ser fuente de la vida moral", de modo que "los que tienen el poder soberano son guardianes e intérpretes, no sólo del derecho civil, sino también del sagrado, y que únicamente ellos tienen derecho a decidir qué sea lo justo y qué lo injusto, lo que sea conforme o no a la piedad". De ahí la conclusión de que, "en orden a mantener el derecho de la mejor manera posible y asegurar la estabilidad del Estado, conviene dejar a cada uno libre de pensar lo que quiera, y de decir lo que piense" ${ }^{\prime 30}$.

${ }^{28}$ Negro, Dalmacio, El Estado moral de Rousseau, en Anales de la Real Academia de Ciencias Morales y Políticas, 83 (Madrid, 2006), pp. 231 ss. También puede verse, del mismo autor, El mito del hombre nuevo (Madrid, Encuentro, 2009), p. 122, en lo que toca a Hegel.

${ }^{29} \mathrm{Cfr}$. Ayuso, Miguel (editor), Política católica e ideologías. Monarquía, tecnocracia y democracias (Madrid, Itinerarios, 2015), en particular los capítulos de la primera parte de John Rao (sobre la democracia representativa), Dalmacio Negro (sobre la democracia partidocrática) y Felipe Widow (sobre la democracia deliberativa). Y el libro de SEgOvia, Juan Fernando, Habermas y la democracia deliberativa. Una utopía tardomoderna (Madrid, Marcial Pons, 2008).

${ }^{30}$ SpInOzA, Baruch, Tractatus theologico-politicus (1670), prefacio. El capítulo 
¡Qué interesante! La libertad de conciencia y de religión constituye el medio más seguro para que el Estado se afirme como fuente única de la moralidad. Así descristianiza el liberalismo. Como había visto León XIII al señalar que viene del ateísmo el que el Estado conceda a todas las religiones iguales derechos ${ }^{31}$.

En realidad estamos viendo esto en la vida política interna de los Estados y en la vida internacional: "Hay que reconocer que sea desde la ONU, como desde los poderes políticos estatales, ni se espera ni se aceptaría un juicio moral venido del mundo religioso. Sociológica y culturalmente, nos encontramos con la trágica exclusividad del mahometismo en aparecer como una resistencia explícita a la secularización del laicismo en nuestra vida colectiva. Si se hubiese atendido a los procesos reales que hemos presenciado y que han llevado a la descristianización de la cristiandad occidental, tendríamos que reconocer dos hechos importantísimos y de significado decisivo. En primer lugar, la injusticia sectaria que ha hecho

$20^{\circ}$, incluso en el título, desarrolla la conclusión. Cfr. Canals, Francisco, Por qué descristianiza el liberalismo, en Verbo, 439-440 (Madrid, 2005), pp. 439 ss. Escribe Canals: "El Tractatus theologico-politicus de Spinoza fue escrito en 1670. Fue más conocido como el punto de partida de los criterios metafísicos y epistemológicos que pusieron en marcha la lectura racionalista y modernista de la Sagrada Escritura, pero ejerció una inspiración profunda en lo más originario y auténtico del pensamiento liberal. Parece muy probable que el verdadero creador del edificio político americano, Thomas Jefferson, aparentemente 'unitariano' era, en su pensamiento profundo, un discípulo de Spinoza, porque hacía ya tiempo que el unitarianismo, que se presentaba como 'negador de la Trinidad', había evolucionado en la dirección del monismo panteísta y naturalista que se había expresado en forma tan explícita en la obra del judío no creyente, sino 'filósofo', Baruch de Spinoza. Los católicos liberales del siglo XIX ponían en duda el acierto y la justicia de las condenaciones pontificias sobre el liberalismo, e inspiraron prácticamente la aceptación de los principios liberales. Si hubiesen atendido a las fuentes filosóficas del liberalismo, hubieran comprendido el profundo acierto de las condenaciones de la Iglesia. En realidad, el Estado moderno de inspiración filosófica deriva prácticamente del panteísmo que con formulaciones de un monismo estático spinoziano o de un monismo dialéctico hegeliano, vino a reinar en el Occidente apóstata del cristianismo a partir de la Revolución francesa. La primera proposición del Syllabus de Pío IX contiene una admirable síntesis de todos los errores contemporáneos en esta su doble raíz spinoziana y hegeliana. La proposición condenada dice así: "No existe ningún poder divino supremo sapientísimo y providentísimo, distinto de la universalidad de las cosas, y Dios es idéntico con la naturaleza y, por lo mismo, sometido a cambio, y en realidad Dios se realiza en el hombre y en el mundo, y todas las cosas son Dios, y tienen la mismisima substancia de Dios, y una y la misma cosa es Dios y el mundo y, por consiguiente, el espiritu y la materia, la necesidad y la libertad, lo verdadero y lo falso, lo bueno y lo malo, lo justo y lo injusto" (DS núm. 2901)" (pp. 821-822).

${ }^{31}$ LEÓN XIII, Inmortale Dei (1885), núm. 10. 
evolucionar el Estado separado de la Iglesia hacia el Estado laicista opresor del derecho a la presencia de la fe en la educación y en la vida social, que no es algo contradictorio con los principios del liberalismo que la Iglesia condenó, ni accidental a su dinamismo profundo. En segundo lugar, la hegemónica influencia del sectarismo anti-cristiano en los medios de comunicación social y en todos los ámbitos culturales que han conformado la mentalidad contemporánea anti-teística es algo no sólo coherente con los principios del liberalismo, sino algo intentado por "principios" explícitamente afirmados como la finalidad del propio liberalismo desde sus fuentes filosóficas originarias y capitales" ${ }^{\prime 2}$.

\section{EL EsTADO DÉBIL}

Giambattista Vico teorizó lo que se ha difundido luego con la expresión "heterogénesis de los fines", esto es, consecuencias no queridas -hasta el punto de alcanzar lo contrario de lo intentado- de acciones queridas ${ }^{33}$. Esto es lo que ha ocurrido en el asunto que nos ocupa. Y es que el "Estado ético" iba a producir primeramente la volatilización de la ética y finalmente la desaparición del propio Estado.

En efecto, el "Estado ético" se ve obligado a absorber la ética en el derecho, o mejor, en la legislación, sea ésta producto de la voluntad del Estado o fruto de las llamadas "opciones compartidas": "La ética y el derecho no tendrían ninguna consistencia: de bien y de justo sólo sería posible hablar en un sentido relativista; lo que se entiende bueno y justo lo sería tan sólo con referencia a la voluntad cambiante del Estado o a un contexto social que instituye convencionalmente estos dos criterios" ${ }^{34}$. Las consecuencias que derivan de lo anterior no son pocas ni pequeñas. En especial, de ser rigurosos en la aplicación de las premisas, debiera considerarse ilegítima toda "imposición" y, consiguientemente, la educación o -en otro orden- el bautismo administrado a los menores, pero también

${ }^{32}$ Canals, Francisco, cit. (n. 30), p. 824.

${ }^{33} \mathrm{El}$ asunto es complejo, pues Vico parece referirse -como un precursor de Adam Smith y su "mano invisible" - a cómo la búsqueda de lo útil individualmente se resuelve en la obtención de lo que beneficia a todos según los designios de la Providencia. Véanse Opere di Giambattista Vico: Principij scienza nuova d intorno alla commune natura delle nazioni (edición de Giuseppe Ferrari, Milano, Società Tipografica dei Clasici Italiani, 1836), II, p. 619. Se trata de la edición de 1744 y se halla en la conclusión. En castellano podemos ver, entre las ediciones asequibles, la de J. M. Bermudo (Barcelona, Orbis, 1985), II, p. 240, parágrafo 1108. La acepción que se ha difundido, en cambio, es la que mencionamos en el cuerpo de este escrito.

${ }^{34}$ Mattiusi, Daniele, Stato etico e Stato di diritto: un appunto, en Instaurare, 38 (Udine, 2009) 2, p. 2. 
las terapias practicadas a éstos (más aún cuando son preventivas como las vacunas) y aun la concepción y el nacimiento ${ }^{35}$. El derecho penal sería también, de resultas, injustificable, y en particular algunos tipos delictivos (como el homicidio consentido o el suicidio intentado, y aun el asistido) supondrían una inconcebible limitación de la libertad ${ }^{36}$.

Ahí radicaría el segundo aspecto de la heterogénesis de los fines mencionada. Pues, entre las metamorfosis de la modernidad, si el Estado no puede prescribir nada y su ordenamiento ha de ser "neutral", puestos ambos al servicio de las decisiones - de cualquier decisión- de la persona, también desaparecen. El Estado, en el seno de la modernidad que podríamos llamar "fuerte", pretendió fundarse sobre el contrato (ahí están las teorías de Hobbes, Locke y Rousseau), sin lograr dar una justificación (que no fuera operativa) de su existencia. Y cuando creyó poder hacerlo a través de un sistema riguroso (en eso consistió el aporte de Hegel) se evidenció la falacia, pues pese a la racionalidad supuesta ha terminado identificándose simplemente con el monopolio del uso de la fuerza o la eficacia en la neutralización de los conflictos y la instauración de un orden público. El Estado, pues, no podía admitir otras realidades fuera de sí mismo, ni tolerar la existencia de ordenamientos o instituciones que no fueran emanación suya. Hasta los derechos humanos no podían verse sino como derechos civiles (del hombre en sociedad) y por lo tanto puestos e impuestos por la soberanía estatal. La disolución de la modernidad "fuerte" y su paso a una fase "débil" no ha cancelado la doctrina de la soberanía, sino que se ha limitado a cambiar de soberano. La persona, así, ha sustituido al Estado, limitado a un aparato de la soberanía popular, esto es, instrumento para la realización de finalidades que no ha escogido sino que proceden de los individuos o los grupos sociales ${ }^{37}$. Era natural, pues exiliado del horizonte moderno el "bien común", e instaurada la contraposición entre lo público y lo privado, si en una primera fase se redujo aquél a puro "bien público", virtualmente totalitario, en otra posterior la más rabiosamente coetánea se ha concluido por asignar al "bien privado" un primado sobre éste. Se ha llegado, así, a la afirmación de lo público exclusivamente en función de lo

${ }^{35}$ Véase, respecto de la educación, a CASTELlano, Danilo, La emergencia educativa. Causas y problemas, en Verbo, 475-476 (Madrid, 2009), pp. 363 ss. En lo que hace a la consideración del nacimiento como un daño resarcible, recuérdese la conocida sentencia de la Corte de Casación francesa de 17 de noviembre de 2000.

${ }^{36}$ Véase Castellano, Danilo (editor), Eutanasia: un diritto? (Napoli, Edizioni Scientifiche Italiane, 2015), en particular los textos del editor del volumen y de monseñor Ignacio Barreiro.

${ }^{37}$ Castellano, Danilo, Estado, ley y conciencia, en Ayuso, Miguel (editor), Estado, ley y conciencia (Madrid, Marcial Pons, 2010), pp. 202 ss. 
privado y a la reducción del Estado a instrumento para alcanzar cualesquiera instancias individuales. En definitiva, a la decadencia del Estado moderno y a la volatilización de la política ${ }^{38}$.

Este proceso se ha concretado en el "Estado débil", que articula dos aspectos distintos pero en el fondo inseparables: el del "Estado mínimo" y el "Estado neutral".

Respecto del primero, cuando el Estado pierde su dimensión moral -se ha escrito agudamente- deja de ser "la concentración estable de las instituciones y los ciudadanos" y se convierte "en el lugar mismo del desorden". La "cosa pública" ya no es ni una cosa ni una realidad: "se encuentra fragmentada, intelectual y concretamente, en tantas opiniones como espíritus, habiendo llegado a convertirse el Estado en lo que de él percibían los ideólogos: "violencia institucionalizada" para los unos, expresión de los intereses burgueses para los otros, distribuidor de larguezas para los más y salteador de caminos para casi todos". Si ha sobrevivido se debe sólo a los grandes feudalismos interesados en disimularse detrás del Estado, al igual que algunos grandes señores se escondían detrás de la corona: "Los feudalismos modernos aceptan entrar en simbiosis con el Estado y unir su burocracia a la de él, con el fin de constituir ese inmenso Estado tutelar descrito por Tocqueville, entidad monstruosa que no se percibe en ningún lugar porque su presencia se halla en todas partes. Estado frágil y todopoderoso, coloso de pies de barro, presa de no importa qué minoría actuante y prevaleciente que hace suyo -como ya lo constató Burckhardt- el programa de cada uno sin contentar a nadie. Su debilidad para afrontar las situaciones concretas - ¿cómo iba a hacerlo, asociando la fuerza y la agresividad con el poder?- multiplica las burocracias, porque es más fácil acallar un problema que resolverlo. Esa es, justamente, la situación del ciudadano del Bajo Imperio, que recibe antes al bárbaro que al recaudador de impuestos" 39 .

${ }^{38} \mathrm{Me}$ he ocupado del asunto en ¿Después del Leviathan? Sobre el Estado y su signo (Madrid, Speiro, 199), y en dos ampliaciones sucesivas: ¿Ocaso o eclipse del Estado? Las transformaciones del derecho público en la era de la globalización (Madrid, Marcial Pons, 2005), y El Estado en su laberinto. Las transformaciones politicas contemporánea (Barcelona, Scire, 2011).

${ }^{39}$ Molnar, Thomas, Ideología y pensamiento de derechas, en Convivencia y respeto social (Madrid, Unión Editorial, 1980), III, pp. 419 ss. El volumen recoge las conferencias pronunciadas en el curso 1979/1980 en el Club Siglo XXI de Madrid. Sigue el escritor húngaro: "Con la ayuda de su red de alianzas con los grandes feudalismos, el Estado convierte a todos los ciudadanos en sus clientes, ya sea de forma directa o de forma indirecta. Y no es la lealtad ni el patriotismo lo que lleva a las gentes a ese estado de sumisión; la verdad que cada cual está inscrito en alguno de los feudalismos actuantes que le mantienen dentro de la obediencia. Cada uno o 
Pero es que, al final, la debilidad deriva igualmente de la pretensión del "Estado neutro", ligado al asunto de la "laicidad" 40 . La "laicidad" no es simple reivindicación de autonomía o de independencia de las realidades temporales, como en el pasado reclamaban diversas doctrinas definidas "laicas", que a veces condujeron al "laicismo", manifestado esencialmente como anticlericalismo. Hoy la laicidad se presenta en términos nuevos, no tanto de "laicidad excluyente" (la exclusión del fenómeno religioso respecto del ordenamiento jurídico) como de "laicidad incluyente" (la inclusión del fenómeno religioso pero como derecho al ejercicio de la libertad negativa y no como deber ejercitado en la libertad). Desde este prisma la laicidad consistiría en la emancipación como realización integral de la libertad negativa, que se convierte en laicismo cuando asume una posición militante. Dos son las formas que hoy asume la laicidad, las "vías" francesa y americana. La primera privilegia los derechos de la identidad colectiva y reivindica el poder de organizar la sociedad según un orden convencional cualquiera. En la segunda, que se ha extendido más allá del ámbito en que nació a causa de las aporías de la anterior, es el individuo y no el Estado quien tendría el derecho de ejercitar la libertad negativa, y el ordenamiento jurídico estatal sería instrumental a la voluntad individual ${ }^{41}$.

es funcionario del Estado, o es miembro de un sindicato, o militante de un partido, o empleado de una gran empresa, o relacionado con los medios de comunicación. Y así, al mismo tiempo que sufre el peso del Estado, apenas mitigado por la pertenencia a los grandes grupos de interés, el espacio político existente entre el individuo y el Estado se encoge catastróficamente a causa del debilitamiento de las instituciones y de los cuerpos intermedios. En el fondo, el liberalismo es eso justamente: la sustitución de las instituciones, llamadas tiránicas en el siglo XVIII, por los grupos de presión que nadie controla y frena [...]. El liberalismo lo demolió todo en nombre de la libertad y después alentó la reconstrucción de los poderes encubiertos. Todo, hasta el propio socialismo, tiene su origen en esta falsificación liberal: el mismo socialismo se ha convertido en un feudalismo, en una demagogia, en un grupo de presión, jay!, popular, porque promete la vuelta de una mayor humanidad, de una mayor solidaridad". Puede verse el intercambio de pareceres entre Thomas Molnar, Juan Vallet de Goytisolo y quien escribe en Verbo, 341-342 (Madrid, 1996), pp. 85 ss., editado también separadamente bajo el título A vueltas con la sociedad civil.

${ }^{40}$ Puede verse a este respecto mi libro La constitución cristiana del Estado (Barcelona, Scire, 2008), en particular la conclusión y el número 445-446 de la revista Verbo (Madrid, 2006).

${ }^{41}$ Castellano, Danilo, Orden ético y derecho, cit. (n. 18), pp. 41-50. Pero si la laicidad francesa caía en la contradicción representada por el hecho de que para afirmarse verdaderamente debería sostener la indiferencia respecto de toda opción o proyecto, la americana se ve obligada a recurrir al "orden modular" para escapar de las propias contradicciones. Lo explica a las pp. 47-50. 
Por ahí aparece, finalmente, una nueva heterogénesis de los fines: pues es la propia persona, reducida a un haz de pulsiones, la que desaparece ${ }^{42}$.

Todavía un breve apunte sobre el impacto de esta concepción en el pensamiento católico, que -apodándola de "positiva" o "nueva"- la ha asumido erróneamente. La vía (rectius, una de las vías) no ha sido otra que la libertad de conciencia y religión. Y es que la laicidad, significa, sobre todo, una posición de autonomía en el orden de la indiferencia y, por tanto, la reivindicación de la libertad de pensamiento y de conciencia como condiciones de independencia frente a la realidad y la ética (entendida como orden moral), así como cualquier autoridad. Lo explica muy claramente: "La tesis según la cual la libertad de religión lleva consigo la laicidad puede parecer, a primera vista, paradójica. Quizá sea contraria a la doxa, esto es, contra la opinión corriente pero que no es sostenible. Si se considera, en efecto, lo que se ha dicho, por más que brevemente, parece claro que la libertad de religión es la negación de toda religión. Negación, sobre todo, de toda religión revelada, a la que sólo se puede adherir siempre que se la transforme en creencia y en sentimiento personal, modificando así -si fuera posible- la naturaleza de la misma religión. La libertad de religión no es otra cosa-como acabamos de decir-que la pretensión a ver reconocida como legítima la propia creencia (incluso la atea) y, por ello, a ver reconocido el "derecho" a su profesión en público y en privado. Lo que no es sinónimo de "no coerción" en lo que toca a la fe y a la adhesión a la Iglesia. Es mucho más. Y, sobre todo, es algo distinto. Rosmini diría que es una forma radical de impiedad" ${ }^{3}$.

\section{EL ESTADO MORALIZADOR}

Anterior el Gobierno al Estado, pues aquél es perenne y éste histórico, la decadencia del segundo hubiera podido determinar el retorno del primero. El nihilismo rampante -en cambio- lo ha impedido, determinando el brote de un subrogado suyo: el de la gobernanza o, más propiamente, el desgobierno de la globalización ${ }^{44}$.

${ }^{42}$ Respecto de la disolución de la persona al mismo tiempo que de la moral, el derecho o la política, puede verse, de Castellano, Danilo, L'ordine político-ginidico "modulare" del personalismo contemporáneo (Napoli, Edizioni Scientifiche Italiane, 2007).

${ }^{43}$ Castellano, Danilo, ¿Es divisible la modernidad? en Verbo, 515-516 (Madrid, 2013), p. 254.

${ }^{44}$ Véase el capítulo $2^{\circ}$ de ¿Ocaso o eclipse del Estado? y el $5^{\circ}$ de El Estado en su laberinto, ambos ya citados. Así como también Gouvernance, gouvernement et État, en Droit Prospective, 122 (Aix-en-Provence, 2008), pp. 1053 ss. 
El término "gobernanza" ha aparecido con fuerza singular durante los últimos decenios en el seno de la evolución de la democracia representativa, degradada en el Estado de partidos, atacada en apariencia por la tecnocracia y profundizada en la llamada democracia deliberativa. Ésta, en efecto, a partir del consenso moderno, comporta que las instituciones -vaciadas de cualquier finalidad objetiva y convertidas en un recipiente que puede llenarse de cualquier cosas- se pongan al servicio de lo mayoritario o prevalente en el seno de la sociedad. Eso implica la desaparición del gobierno, reducido a gobernanza, esto es, gestión de las deliberaciones que certifican el consenso provisional. De ahí que pueda afirmarse que al consenso, como pseudo-fundamento del gobierno, debe seguir la gobernanza, como pseudo-método de toma de decisiones. Ésta, finalmente, no puede sino menoscabar la democracia representativa, ya que concluye en un autoritarismo 'soft', cuyo objetivo casi confesado es el de "despolitizar" los asuntos públicos, alejándolos lo más posible de los humores de electores versátiles" ${ }^{25}$. En suma, como se ha escrito aceradamente, un krátos sin démos ${ }^{46}$.

La gobernanza, dirigida-según la profecía del conde Saint-Simon-a la administración de las cosas más que al gobierno de las personas ${ }^{47}$, parecía apuntar hacia un Estado debilitado convertido en una pura "máquina económica". Sin embargo, la ingeniería social que ha hecho acto de presencia conforme el Estado providencia desaparecía de la escena más o menos discretamente, nos ha hecho ver cómo también reúne la condición de "máquina ideológica": pretende modificar el comportamiento de los ciudadanos, su visión del hombre y del mundo, e imponerles por ahí una nueva forma de moral. Es el Estado "moralizador", que no puede dar sino lecciones, y que -descalificado en el campo económico y social- encuentra en la tarea de la "moralización" una salida a su impotencia. Con diferentes medios, del derecho "blando" movido (en apariencia) por buenas intenciones (piénsese en la salud o el deporte) al "duro" que se impone por prohibiciones (como en la circulación de vehículos sin ir más lejos) ${ }^{48}$.

Como en el Estado ético, aunque bajo otras formas, lo que no se deja ver por parte alguna es la moral. Y es que el Estado no debe ser ni ético ni moralizador, en los sentidos apuntados, sino que debe subordinarse a

${ }^{45}$ Hermet, Guy, Démocratie et autoritarisme (Paris, Cerf, 2012), p. 254.

${ }^{46}$ Manent, Pierre, La raison des nations (Paris, Gallimard, 2006), pp. 16 ss.

${ }^{47}$ Véase SCIACCA, Michele Federico, Desde el sansimonismo a la tecnocracia de hoy, en Verbo, 103 (Madrid, 1972), pp. 281 ss.; Vallet De Goytisolo, Juan, Tecnocracias, totalitarismo, masificación, en Verbo, 103 (Madrid, 1972), pp. 742-743.

${ }^{48}$ Véase Groulier, Cédric (editor), L'État moralisateur (Paris, Mare et Martin, 2014). 
la ética o la moral. Ese sería (pese a las dificultades terminológicas que se suscita y que, tras lo anterior, se comprenderán sin dificultad) el verdadero "Estado ético". El que está intrínsecamente ordenado. El que persigue el bien común y, consiguientemente, no puede desentenderse de la verdad ${ }^{49}$. El que respeta la invariante moral del orden político ${ }^{50}$. El Estado católico, en resumidas cuentas, que no se basa tanto en razones de fe como y sobre todo de razón ${ }^{51}$.

\section{BibLIOGRAFíA}

Almoguera, Joaquín, El ordenamiento del derecho: orden ético, orden politico y orden estatal, en Verbo, 487-488 (Madrid, 2010).

Ambrosetti, Giovanni, L'essenza dello Stato (Brescia, La Scuola, 1973).

Aristóteles, Ética a Nicómaco.

Ayuso, Miguel (editor), Politica católica e ideologías. Monarquía, tecnocracia y democracias (Madrid, Itinerarios, 2015).

Ayuso, Miguel, ¿Ocaso o eclipse del Estado? Las transformaciones del derecho público en la era de la globalización (Madrid, Marcial Pons, 2005).

Ayuso, Miguel, De la ley a la ley. Cinco lecciones sobre legalidad y legitimidad (Madrid, Marcial Pons, 2001).

AYuso, Miguel, El Estado en su laberinto. Las transformaciones politicas contemporánea (Barcelona, Scire, 2011).

Ayuso, Miguel, La filosofia jurídica y política de Álvaro d’Ors, en Altuve, Fernán (editor), Homenaje a Álvaro d' Ors (Lima, Dupla, 2001).

Ayuso, Miguel, Sobre la ética pública. Una visión problemática, en Verbo, 491-492 (Madrid, 2011).

Ayuso, Miguel, La constitución cristiana del Estado (Barcelona, Scire, 2008).

Ayuso, Miguel.¿Después del Leviathan? Sobre el Estado y su signo (Madrid, Speiro, 199). Bodino, Los seis libros de la República.

Canals, Francisco, Por qué descristianiza el liberalismo, en Verbo, 439-440 (Madrid, 2005).

Castellano, Danilo (editor), Eutanasia: un diritto? (Napoli, Edizioni Scientifiche Italiane, 2015).

Castellano, Danilo, ¿Es divisible la modernidad? en Verbo, 515-516 (Madrid, 2013).

${ }^{49}$ Puede verse Ambrosetti, Giovanni, L'essenza dello Stato (Brescia, La Scuola, 1973), y Gentile, Marino, Il filosofo di fronte allo Stato moderno (Napoli, Scalabrini, 1964), según los cuales, respectivamente, "la esencia del Estado plantea necesariamente el problema de la verdad" y "el Estado es el instrumento que, en el orden querido por Dios, se nos ha dado para que disciplinándonos lleguemos mejor a ser hombres".

${ }^{50}$ Guerra Campos, José, La invariante moral del orden politico, en VV. AA. Hacia la estabilización política, (Madrid, 1983), III, pp. 101 ss. Se trata de una conferencia pronunciada por el a la sazón obispo de Cuenca en el Club Siglo XXI.

${ }^{51}$ Véase Ayuso, Miguel, La constitución cristiana de los Estados, cit. (n.40), en particular el capítulo $4^{\circ}$. 
Castellano, Danilo, Estado, ley y conciencia, en Ayuso, Miguel (editor), Estado, ley y conciencia (Madrid, Marcial Pons, 2010).

Castellano, Danilo, L'ordine della politica (Napoli, Edizioni Scientifiche Italiani, 1997).

Castellano, Danilo, L'ordine político-giuidico “modulare" del personalismo contemporáneo (Napoli, Edizioni Scientifiche Italiani, 2007).

Castellano, Danilo, La emergencia educativa. Causas y problemas, en Verbo, 475-476 Madrid, 2009).

Castellano, Danilo, La naturaleza de la política (Barcelona, Scire, 2006).

Castellano, Danilo, La razionalità della politica (Napoli, Edizioni Scientifiche Italiani, 1993).

Castellano, Danilo, Orden ético y derecho (Madrid, Marcial Pons, 2010).

Clément, Marcel, Catéchisme de sciences sociales (Paris, Nouvelles Éditions Latines, 1959).

Clément, Marcel, Charles de Koninck et les sciences sociales, en Itinéraires, 66 (Paris, 1962).

Crespo, Ricardo, El acto humano: Aristóteles y Tomás de Aquino, en Sapientia, 51 (Buenos Aires) 199 (1996).

CRESPO, Ricardo, La ciencia práctica y sus características: ensayo de sistematización y aplicación a la economía, en Analogía Filosófica. Revista de Filosofia, Investigación y Difusión, 11 (Ciudad de Méjico, 1997), 2.

D'Ors, Álvaro, Nueva introducción al estudio del derecho (Madrid, Civitas, 1999).

D'Ors, Álvaro, Una introducción al estudio del derecho (8a edición, Madrid, Rialp, 1989).

DE CorTe, Marcel, L'homme contre lui-même (Paris, Nouvelles Éditions Latines, 1962).

DE Koninck, Charles, Sciences morales et sciences sociales, en Laval Philosophique et Théologique, 1 (Québec, 1945) 2.

ElíAS DE TEJADA, Francisco, La monarquía tradicional (Madrid, Rialp, 1954).

Gentile, Francesco, Intelligenza politica e ragion di Stato (2a edición Milano, Giuffrè, 1984).

Gentile, Marino, Il filosofo di fronte allo Stato moderno (Napoli, Scalabrini, 1964).

Groulier, Cédric (editor), L'État moralisateur (Paris, Mare et Martin, 2014).

Guerra Campos, José, La invariante moral del orden político, en VV. AA. Hacia la estabilización politica (Madrid, 1983), III.

Hermet, Guy, Démocratie et autoritarisme (Paris, Cerf, 2012).

LEÓN XIII, Inmortale Dei (1885).

Lutero, Martín, Weimarer Ausgabe.

Manent, Pierre, La raison des nations (Paris, Gallimard, 2006).

Mattiusi, Daniele, Stato etico e Stato di diritto: un appunto, en Instaurare, 38 (Udine, 2009) 2.

Molnar, Thomas, Ideología y pensamiento de derechas, en Convivencia y respeto social (Madrid, Unión Editorial, 1980), III.

Negro, Dalmacio, El“éthos": religión y política, en Razón española, 162 (Madrid, 2010).

Negro, Dalmacio, El Estado moral de Rousseau, en Anales de la Real Academia de Ciencias Morales y Politicas, 83 (Madrid, 2006).

Negro, Dalmacio, El mito del hombre nuevo (Madrid, Encuentro, 2009).

Negro, Dalmacio, La metodología jurídica de Vallet de Goytisolo ante la política, en Verbo, 427-428 (Madrid, 2004). 
Rousseau, Jean-Jacques, Considérations sur le gouvernement en Pologne.

SCIACCA, Michele Federico, Desde el sansimonismo a la tecnocracia de hoy, en Verbo, 103 (Madrid, 1972).

SEgovia, Juan Fernando, Habermas y la democracia deliberativa. Una utopía tardomoderna (Madrid, Marcial Pons, 2008).

SPINOZA, Baruch, Tractatus theologico-politicus (1670).

STrauss, Leo, Natural Right and History (Chicago, Chicago University Press, 1950).

VAllet De Goytisolo, Juan, La nueva concepción de la vida social de los pactistas del siglo XVII: Hobbes y Locke, en Verbo, 119-120 (Madrid, 1973).

Vallet de Goytisolo, Juan, Poderes politicos y poderes sociales. Totalitarismo y distribución de poderes, en Verbo, 285-286 (Madrid, 1990).

Vallet de GoYTisolo, Juan, Tecnocracias, totalitarismo, masificación, en Verbo, 103 (Madrid, 1972).

VICO, Giambattista, Opere di [...]: Principi scienza nuova d'intorno alla commune natura delle nazioni (edición de Giuseppe Ferrari, Milano, Società Tipografica dei Clasici Italiani, 1836), II.

Widow, José Luis, Introducción a la ética (Santiago de Chile, 2009).

Widow, José Luis, La naturaleza política de la moral (Santiago de Chile, 2004). 
